\title{
Kajian Pengembangan Ekowisata Salang Pangeran Di Kawasan Taman Nasional Gunung Leuser
}

\author{
Iskandarrudin ${ }^{* 1,2}$, Syamsul Arifin ${ }^{3}$, Budi Utomo ${ }^{4}$ \\ ${ }^{1}$ Mahasiswa Program Magister Program Studi Pengelolaan Sumberdaya Alam \\ dan Lingkungan USU \\ ${ }^{2}$ Fungsional Pengendali Ekosistem Hutan, Balai Besar TNGL, Medan \\ ${ }^{3}$ Staf Pengajar Fakultas Hukum, USU, Medan \\ ${ }^{4}$ Staf Pengajar Fakultas Kehutanan, USU, Medan \\ *Koresponden email: iscand.2011@gmail.com
}

Masuk: 4 November 2017

Diterima: 11 November 2017

\begin{abstract}
Development of ecotourism is one way to preserve the forest and also for the welfare of the surrounding community. Salang Pangeran ecotourism in Timbang Lawan village is part of the buffer of Gunung Leuser National Park. Since 2014, people of Timbang Lawan village have opened the Salang Pangeran ecotourism for public. Tourists who visit the ecotourism increase significantly. The purpose of this study is to determine the value of potential objects and natural attractions, internal and external factors that affect the development of Salang Pangeran ecotourism and its development strategies. Methods of data collection by conducting literature studies, field observations, interviews with communities and stakeholders and conducting Focus Group Discussions (FGDs). Data analysis on the potential of Objects and Natural Tourist Attraction (ODTWA) described descriptively and it processed by using Guidance Analysis of the Operational Area-Objects and Natural Tourist Attraction (ADO-ODTWA) and SWOT analysis to formulate strategic alternatives. The results of ODTWA analysis in the Salang Pangeran ecotourism area for each criterias are known for attractiveness value is 1260 points (high), accessibility, 725 points (medium), condition of socio-economic environment, 425 points (medium), accommodation, 180 points (high), insfrastructure and supporting facilities, 300 points (high) and availability of clean water, 900 points (high). There are 9 alternative strategies for the Salang Pangeran ecotourism development plan.
\end{abstract}

Keywords : Salang Pangeran Ecotourism, Attraction, Alternative Strategies, Development

Abstrak. Pengembangan ekowisata merupakan cara menjaga kelestarian hutan untuk kesejahteraan masyarakat di sekitarnya. Ekowisata Salang Pangeran di Desa Timbang Lawan merupakan kawasan yang berada di penyangga Taman Nasional Gunung Leuser. Sejak tahun 2014 masyarakat Desa Timbang Lawan telah membuka Ekowisata Salang Pangeran. Wisatawan yang berkunjung ke Ekowisata Salang Pangeran terus mengalami peningkatan. Penelitian ini dilakukan bertujuan untuk mengetahui nilai potensi objek dan daya tarik wisata alam, faktor internal dan eksternal yang mempengaruhi pengembangan ekowisata Salang Pangeran serta strategi pengembangannya. Metode pengumpulan data dengan melakukan studi literatur, observasi lapangan, wawancara dengan masyarakat dan stakeholder dan melakukan FGD. Analisis data terhadap potensi objek dan daya tarik wisata alam (ODTWA) diuraikan secara deskriptif dan diolah dengan menggunakan pedoman Analisis Daerah Operasi Objek dan Daya Tarik Wisata Alam (ADO-ODTWA) serta analisis SWOT untuk merumuskan alternatif-alternatif strategi. Hasil analisis ODTWA di kawasan ekowisata Salang Pangeran untuk masing-masing kriteria diketahui daya tarik dengan nilai 1260 (tinggi), aksesibilitas dengan nilai 725 (sedang), kondisi lingkungan sosial ekonomi dengan nilai 425 (sedang), akomodasi dengan nilai 180 (tinggi), sarana prasarana penunjang dengan nilai 300 (tinggi) dan ketersediaan air bersih dengan nilai 900 (tinggi).

Kata kunci : Ekowisata Salang Pangeran, Daya Tarik, Alternatif Strategi, Pengembangan 


\section{Pendahuluan}

Pengembangan ekowisata dengan pengelolaan bersama masyarakat sekitar dapat meningkatkan kesejahteraan dan peran serta masyarakat dalam melestarikan kawasan (Purnomo et al. 2013). Aset produksi dalam konsep pengelolaan ekowisata adalah sumberdaya alam dan lingkungan yang masih terjaga kelestariannya.

Salah satu desa yang langsung berbatasan dengan kawasan TNGL di Kecamatan Bahorok adalah Desa Timbang Lawan. Menurut Profil Desa Timbang Lawan Tahun 2017 bahwa Ekowisata Salang Pangeran terletak di Dusun VIII, Desa Timbang Lawan, Kecamatan Bahorok Kabupaten Langkat. Jarak lokasi Ekowisata Salang Pangeran ke Ibu Kota Kecamatan sejauh 5 km, berjarak 80 km dari Ibu Kota Kabupaten Langkat di Stabat, dan berjarak $90 \mathrm{~km}$ dari Medan. Desa Timbang Lawan merupakan desa yang cukup luas di Kecamatan Bahorok dengan luas 100,85 $\mathrm{km}^{2}$ atau 9,15\% dari total luas Kecamatan Bahorok (BPS, 2016).

PHKA (2002) menjelaskan bahwa keanekaragaman hayati, keunikan dan keaslian budaya tradisional, keindahan bentang alam, gejala alam serta peninggalan sejarah/budaya adalah anugerah Tuhan yang berpotensi sebagai objek dan daya tarik wisata alam (ODTWA). Daya tarik di ekowisata Salang Pangeran yaitu aliran sungai Landak yang masih jernih dan banyak terdapat batu-batu, terdapat goa dan air terjun yang mudah dijangkau, terdapat bunga bangkai (Amorphophallus titanium) yang mudah dijumpai, terdapat berbagai jenis satwa liar seperti orangutan sumatera (pongo abelii), siamang atau gibbon (Shymphalangus syndactylus), beruang madu (Helarctos malayanus) dan harimau sumatera (Panthera tigris sumatrensis) (Wind, 1996). Panorama sungai Landak, goa-goa dan tumbuhan langka merupakan daya tarik yang menjadi ciri khas Salang Pangeran. Keberadaan satwa liar merupakan daya tarik di Salang Pangeran namun tidak selalu bisa dilihat secara langsung (BBTNGL, 2016).

Sudana (2013) dalam penelitiannya menggunakan analisis faktor internal yaitu kekuatan dan kelemahan serta faktor eksternal yaitu peluang dan ancaman dalam merumuskan Kajian pengembangan Desa Wisata Ekologis di Desa Belimbing, Kabupaten Tabanan, Bali. Menurut
Nugraha et al. (2015) serta sesuai Beljai et al. (2014) dan Rahantoknam et al. (2012) dalam konsep penataan lanskap dan pengembangan ekowisata Salang Pangeran dilakukan dalam kurun waktu jangka pendek, jangka menengah dan jangka panjang untuk membuat perencanaan yang sesuai dengan kondisi di ekowisata Salang Pangeran dengan mempertimbangkan kondisi geografis yang disesuaikan dengan peraturanperaturan yang berlaku.

Menurut MacKinnon et al. (1993) faktor-faktor yang membuat suatu kawasan hutan menjadi menarik untuk dikunjungi bagi pengunjung adalah :

1. Letaknya dekat, cukup dekat atau jauh dengan bandar udara internasional atau pusat wisata

2. Perjalanan ke kawasan tersebut mudah dan nyaman, perlu sedikit usaha, sulit atau berbahaya.

3. Kawasan tersebut memiliki atraksi yang menonjol misalnya satwa liar yang menarik atau khas untuk tempat tertentu

4. Kemudahan untuk melihat atraksi atau satwa liar dijamin

5. Terdapat beberapa alasan yang mendorong atau memotivasi seseorang untuk berwisata.

6. Memiliki budaya yang menarik

7. Unik dalam penampilannya

8. Mempunyai objek rekreasi pantai, danau, sungai, air terjun, kolam renang, atau tanpa rekreasi lainnya

9. Cukup dekat dengan lokasi lain yang menarik wisatawan sehingga dapat menjadi bagian kegiatan wisata lainnya

10. Sekitar kawasan itu memiliki pemandangan indah

11. Keadaan makanan dan akomodasi tersedia

Berdasarkan uraian tersebut diatas diperlukan suatu kajian pengembangan ekowisata sehingga menjadi kawasan yang lestari khususnya bagi kawasan TNGL serta meningkatkan kesejahteraan masyarakat sekitar hutan.

\section{Metodologi}

Pengumpulan data menggunakan metode kualitatif dengan melakukan wawancara semi terstruktur secara mendalam terhadap key informan (informan kunci), Focus Group Discussion (FGD), studi 
Tabel 1. Pengunjung Ekowisata Salang Pangeran

\begin{tabular}{ccc}
\hline Tahun & Wisatawan Nusantara & Wisatawan Mancanegara \\
\hline 2014 & 5.000 & 650 \\
2015 & 5.600 & 800 \\
2016 & 7.000 & 930 \\
\hline Jumlah & 17.600 & 2.380
\end{tabular}

Sumber : BPMD (2016)

literatur, dan observasi di lapangan.

\subsection{Analisis ODTWA}

Hasil pengolahan data mengenai objek dan daya tarik wisata alam diuraikan secara deskriptif. Data mengenai potensi ODTWA diolah dengan menggunakan Pedoman Analisis Daerah Operasi Objek dan Daya Tarik Wisata Alam (ADO-ODTWA) Direktorat Jenderal PHKA (2003a) yang telah dimodifikasi sesuai dengan nilai/skor yang telah ditentukan untuk masingmasing kriteria. Jumlah nilai untuk satu kriteria penilaian ODTWA dapat dihitung dengan persamaan sebagai berikut :

$\mathbf{S}=\mathbf{N} \times \mathbf{B}$

Keterangan : $\mathrm{S}=$ skor/nilai suatu kriteria

$\mathrm{N}=$ jumlah nilai unsur -unsur pada kriteria

$\mathrm{B}=$ bobot nilai

Potensi objek dan daya tarik wisata alam meliputi daya tarik, aksesibilitas, kondisi lingkungan sosial ekonomi, akomodasi, saranaprasarana penunjang dan ketersediaan air bersih (PHKA, 2003b).

Komponen-komponen yang diamati yaitu :

1. Daya tarik; unsur yang diamati meliputi keunikan, kepekaan, variasi kegiatan, sumberdaya alam yang menonjol, kebersihan lokasi, keamanan, kenyamanan.

2. Aksesibilitas; unsur yang diamati yaitu kondisi dan jarak jalan darat, tipe jalan.

3. Kondisi lingkungan sosial ekonomi;

4. Akomodasi; dilakukan dengan melihat dan mencari informasi mengenai penginapan dalam radius $15 \mathrm{~km}$ dari objek.

5. Sarana-prasarana penunjang meliputi kantor pos, jaringan telepon, Puskesmas, jaringan listrik, jaringan air minum, rumah makan, pusat perbelanjaan/pasar, bank, toko souvenir/cinderamata.

6. Ketersediaan air bersih; unsur yang diamati meliputi volume, jarak sumber air terhadap lokasi objek, dapat tidaknya/kemudahan air dialirkan ke objek, kelayakan dikonsumsi dan kontinuitas.

\subsection{Analisis SWOT}

Analisis SWOT dalam penelitian ini dilakukan untuk menentukan posisi kondisi saat ini dan strategi pengembangan ekowisata Salang Pangeran yang terintegerasi dengan kepariwisataan yang berdekatan. Analisis SWOT membandingkan antara faktor eksternal (peluang dan ancaman) yang mempengaruhi pengembangan pariwisata alam dengan faktor internal (kekuatan dan kelemahan) dalam pengembangan ekowisata Salang Pangeran. Analisis terhadap faktor Internal dan ekternal yang mempengaruhi pengembangan

Tabel 2. Fasilitas Penunjang di Ekowisata Salang Pangeran

\begin{tabular}{lcl}
\hline \multicolumn{1}{c}{ Fasilitas Penunjang } & Jumlah & \multicolumn{1}{c}{ Keterangan } \\
\hline Warung Kopi \& Kedai & 5 & Milik Perseorangan \\
Warung Nasi & 2 & Milik Perseorangan \\
Toilet Umum & 2 & Milik Perseorangan \\
Jalan Setapak & 1 & Milik Umum \\
Jembatan Gantung & 1 & Milik Umum \\
Pos Jaga dan Retribusi & 1 & Milik Perseorangan \\
\hline Sumber: Survey Lapangan (2017) & &
\end{tabular}


Tabel 3. Penginapan di Ekowisata Salang Pangeran

\begin{tabular}{lcl}
\multicolumn{1}{c}{ Nama Penginapan } & Jumlah Kamar & \multicolumn{1}{c}{ Pemilik } \\
\hline Jungle Hill & 2 & M. Ginting \\
Jungle Hut & 1 & Iwansyah \\
Landak River Inn & 1 & Armansyah \\
Salang Pangeran Guest House & 2 & Darlian Nasution \\
Dedi & 1 & Dedi \\
Landak River Inn & 2 & Amudin \\
Irwan & 2 & Irwan \\
Depari Indah & 3 & Tuahta Sembiring \\
\hline \multicolumn{1}{c}{ Total } & 14 & \\
\hline
\end{tabular}

Sumber: Survey Lapangan (2017)

ekowisata Salang Pangeran dilakukan dengan menggunakan Model matriks IFAS-EFAS dari hasil wawancara dengan berbagai pihak untuk diambil suatu rekomendasi sehingga menjadi acuan dalam penyusunan rencana pengembangan (Rangkuti, 2000).

\section{Hasil dan Pembahasan}

\subsection{Wisatawan di Ekowisata Salang Pangeran}

Menurut BPMD (2016), lembaga Ekowisata Salang Pangeran didirikan pada tahun 2014. Tarif masuk pada awalnya sebesar Rp1.000,- per orang sejak tahun 2015 menjadi Rp2.000,- per orang. Pencatatan jumlah pengunjung dilakukan oleh Lembaga Ekowisata Salang Pangeran sejak tahun 2014, jumlah pengunjung dapat dilihat pada Tabel 1.

Fasilitas penunjang di Ekowisata Salang Pangeran terdiri dari warung kopi dan kedai, warung makan, toilet umum, pos jaga dan retribusi serta jembatan gantung (Tabel 2). Fasilitas lain di sekitar Sungai Landak adalah jalan setapak yang dibangun melalui Program Nasional Pemberdayaan Masyarakat (PNPM) Mandiri Perdesaan (BAPPEDA, 2013).

Masing-masing warung kopi dan kedai berkapasitas 10 orang. Warung buka setiap hari dari pukul 07.00 hingga 22.00 WIB menu yang disajikan adalah makanan khas melayu dan makanan cepat saji. Toilet umum dikenakan biaya Rp.2.000 / orang, ini merupakan fasilitas untuk para pengunjung.

Penginapan di Ekowisata Salang Pangeran saat ini sebanyak 8 tempat, pemilik penginapan adalah penduduk Salang Pangeran (Tabel 3).
Kondisi penginapan yang berada di dalam kawasan ekowisata Salang Pangeran semuanya tidak dilengkapi dengan restoran. Tarif penginapan yang ada berkisar antara Rp100.000,hingga Rp250.000,- per malam (BPMD, 2016). 2

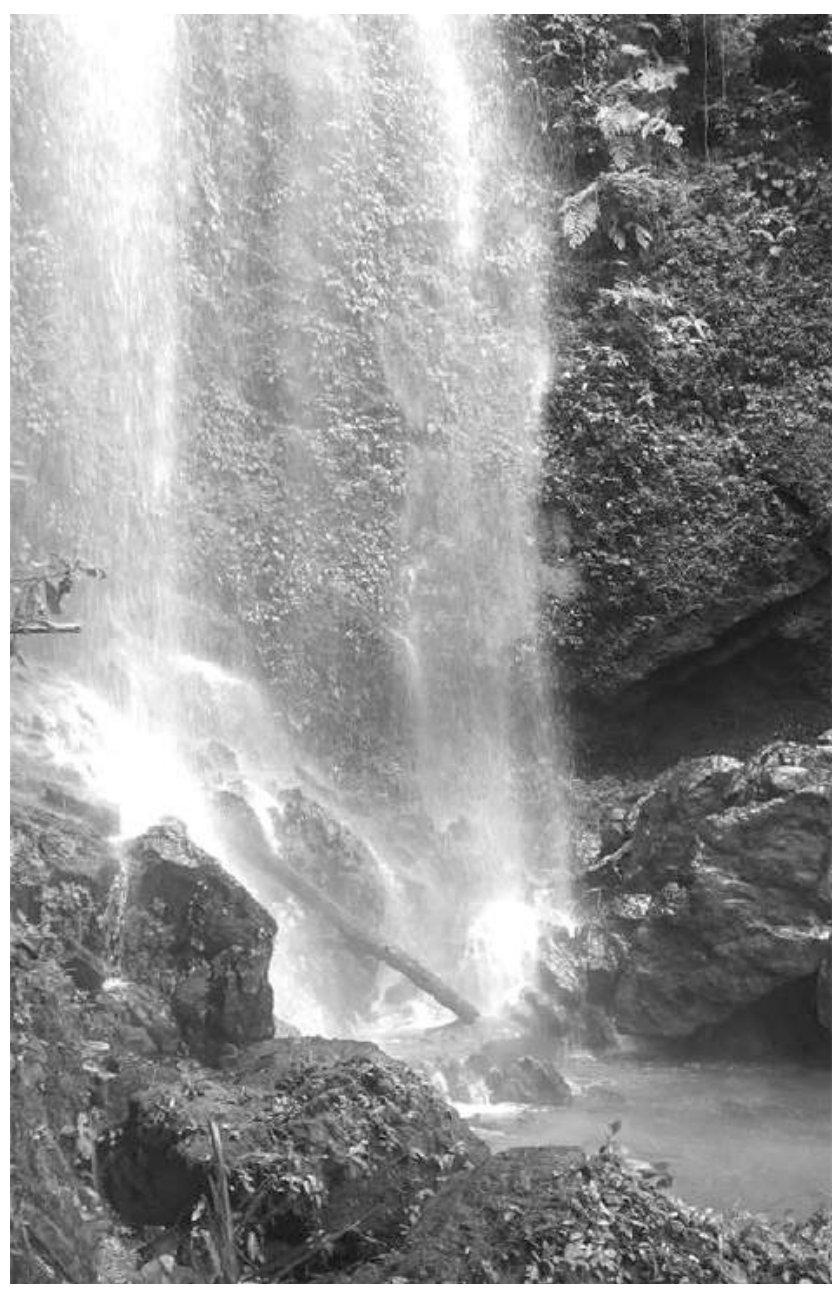

Gambar 1. Air Terjun Salang Pangeran setinggi 30 meter 
Tabel 4. Daya tarik objek wisata alam di kawasan ekowisata Salang Pangeran

\begin{tabular}{|c|c|c|}
\hline No. & $\begin{array}{l}\text { Objek } \\
\text { Alam }\end{array}$ & Daya Tarik \\
\hline 1. & $\begin{array}{l}\text { Air Terjun } \\
\text { Pangeran }\end{array}$ & $\begin{array}{l}\text { - air terjun dengan empat tingkat yang memiliki udara } \\
\text { yang sejuk dan lingkungan yang masih asri dimana } \\
\text { tingkat pertama ketinggian } 10 \text { meter, tingkat kedua } \\
\text { tinggi } 10 \text { meter, tingkat ketiga tinggi } 30 \mathrm{~m} \text { dan } \\
\text { tingkat empat } 5 \text { meter. } \\
\text { Lokasi jatuhnya air terjun juga membentuk telaga } \\
\text { berdiameter } 10 \text { meter dengan kedalaman } 2 \text { meter. } \\
\text { - Kegiatan : menikmati keindahan, tracking, } \\
\text { memancing, berenang, } \\
\text { penelitian/pendidikan, hiking } \\
\text { - Flora : medang, kelat, meranti, rotan, bambu } \\
\text { - Fauna : orangutan, kedih, monyet ekor panjang, } \\
\text { bajing. }\end{array}$ \\
\hline 2. & Sungai Landak & $\begin{array}{l}\text { - Sungai jernih dan dangkal dengan hulu berasal dari } \\
\text { dalam kawasan TNGL. } \\
\text { - Kegiatan : menikmati keindahan, memancing, } \\
\text { tracking, berenang, berkemah, penelitian/pendidikan, } \\
\text { hiking } \\
\text { - Flora: pisang hutan, tepus, jabon, meranti, dan durian } \\
\text { - Fauna : kupu-kupu, burung elang, lutung, monyet } \\
\text { ekor panjang, dan ikan jurung yang terdapat di } \\
\text { sungai }\end{array}$ \\
\hline 3. & Gua Batu Rizal & $\begin{array}{l}\text { - Memiliki stalagmit dan stalaktit yang unik dan } \\
\text { menarik. Terdiri atas banyak ruangan dengan panjang } \\
\text { Gua } 250 \text { meter serta lebar } 20 \text { meter. } \\
\text { - Kegiatan : menikmati keindahan, tracking, berenang, } \\
\text { berkemah, penelitian/pendidikan, caving } \\
\text { - Flora : tidak ditemukan flora di dalam Gua } \\
\text { - Fauna : kelelawar, burung, berbagai jenis serangga, } \\
\text { katak }\end{array}$ \\
\hline
\end{tabular}

Sumber : BBTNGL (2016)

\subsection{Kriteria penilaian ODTWA}

Kriteria penilaian objek wisata alam merupakan suatu instrumen untuk mendapatkan kepastian kelayakan suatu objek untuk dikembangkan sebagai objek wisata alam. Fungsi kriteria adalah sebagai dasar dalam pengembangan ODTWA melalui penetapan unsur kriteria, penetapan bobot, penghitungan masing-masing sub unsur dan penjumlahan dari semua kriteria (Dirjen PHKA, 2003a). Terdapat beberapa lokasi yang berpotensi sebagai objek menarik yaitu Air Terjun Salang Pangeran, Sungai Landak dan Gua Batu Rizal. Objek yang ada di kawasan ekowisata Salang
Pangeran tersebut selanjutnya dinilai menurut kriteria penilaian yang dipakai sebagai dasar dalam penilaian ODTWA ini yaitu daya tarik, aksesibilitas, kondisi lingkungan sosial ekonomi, akomodasi, sarana- prasarana penunjang dan ketersediaan air bersih.

\subsection{Rekapitulasi penilaian ODTWA}

Penilaian ODTWA kawasan ekowisata Salang Pangeran dilakukan terhadap enam kriteria yaitu daya tarik, aksesibilitas, kondisi lingkungan sosial ekonomi, akomodasi, sarana- prasarana penunjang dan ketersediaan air bersih. 


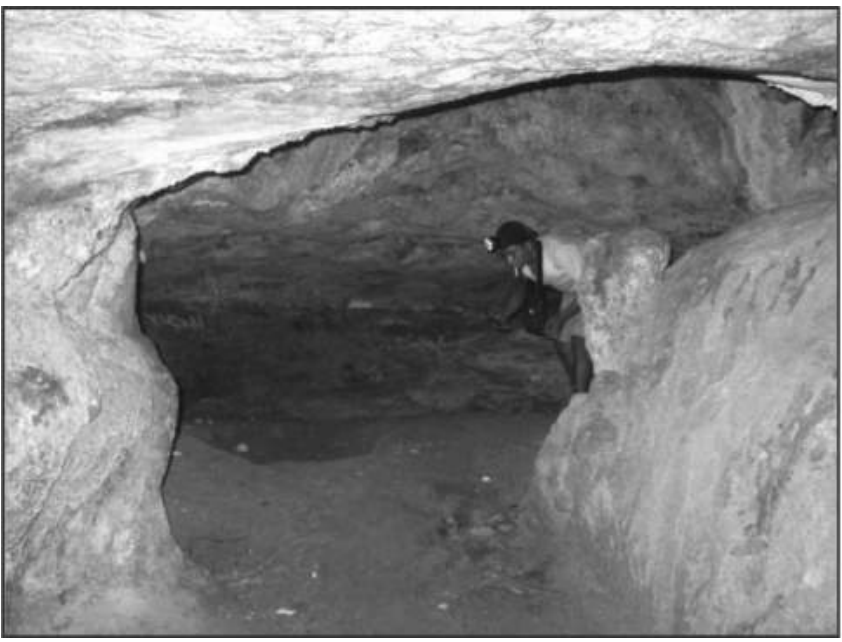

Gambar 2. Pintu masuk Gua Batu Rizal

Berdasarkan Tabel 5. diketahui bahwa objek wisata alam salang Pangeran untuk kriteria daya tarik, akomodasi, sarana-prasarana penunjang dan ketersediaan air bersih bernilai tinggi. Sedangkan kriteria aksesibilitas dan kondisi lingkungan sosial / ekonomi bernilai sedang. Berdasarkan klasifikasi penilaian diatas, objek daya tarik di ekowisata Salang Pangeran ini dapat dijadikan prioritas rencana pengembangan serta membuat perencanaan jenis atraksi wisata yang sesuai yang dapat dikemas seperti berkemah, bersampan, kayaking, rafting, wisata pemandian, wisata penelusuran gua, pengamatan satwa khas gua dan jenis wisata lainnya lainnya (Zahedi, 2002). Namun masih diperlukan pembenahan terhadap objek tersebut dengan menyusun perencanaan

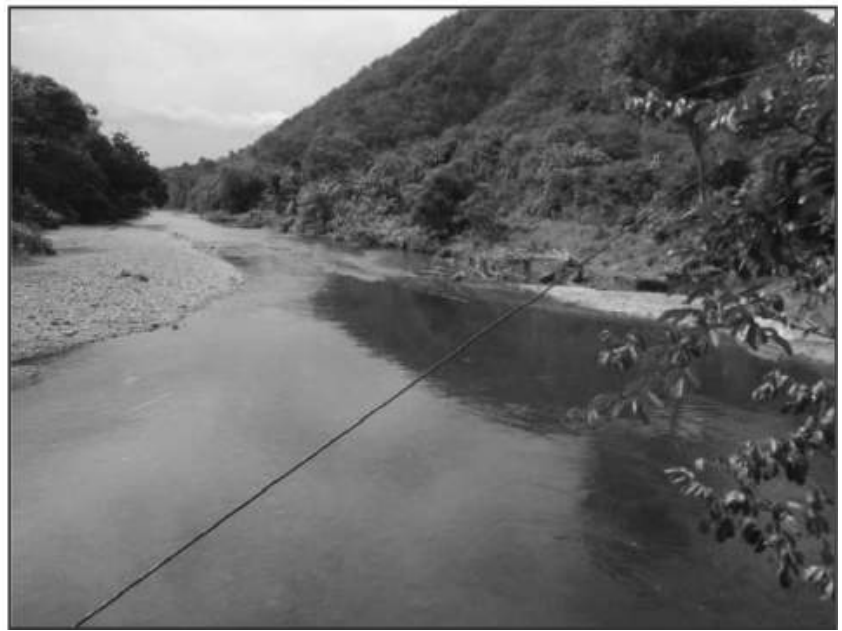

Gambar 3. Sungai sebagai salah satu sumber air bersih di kawasan ekowisata Salang Pangeran

wisata alamnya (Wiranantha et al, 2009).

\section{Analisis Faktor-Faktor Internal dan Faktor-Faktor Eksternal}

\subsection{Analisis faktor-faktor internal}

Hasil analisis IFAS di Ekowisata Salang Pangeran menunjukkan faktor-faktor internal yang menjadi kekuatan (strength) adalah:

1. Daya tarik wisata alam berupa panorama alam terdiri dari sungai, Gua, air terjun dan hutan;

2. Aksesibilitas menuju lokasi Ekowisata Salang Pangeran bisa di jangkau dengan kendaraan roda 2 dari Medan hanya membutuhkan waktu 3 jam;

3. Kesadaran pelaku wisata dan masyarakat

Tabel 5. Klasifikasi kriteria penilaian ADO-ODTWA objek wisata alam Salang Pangeran

\begin{tabular}{|c|c|c|c|c|c|c|c|}
\hline \multirow[b]{2}{*}{ No } & \multirow[b]{2}{*}{ Kriteria Penilaian } & \multicolumn{2}{|c|}{ Nilai } & \multirow[b]{2}{*}{ Interval } & \multicolumn{2}{|c|}{ Nilai Potensi } & \multirow[b]{2}{*}{ Klasifikasi } \\
\hline & & Min & $\operatorname{Max}$ & & Angka & $\%$ & \\
\hline 1. & Daya tarik & 450 & 1260 & 270 & 1260 & 100,00 & tinggi \\
\hline 2. & Aksesibilitas & 300 & 1300 & 333,33 & 725 & 42,50 & sedang \\
\hline 3. & $\begin{array}{l}\text { Kondisi } \\
\text { lingkungan } \\
\text { sosial/ekonomi }\end{array}$ & 250 & 600 & 116,67 & 425 & 50,00 & sedang \\
\hline 4. & Akomodasi & 60 & 180 & 40 & 180 & 100,00 & tinggi \\
\hline 5. & $\begin{array}{l}\text { Sarana-prasarana } \\
\text { penunjang }\end{array}$ & 60 & 300 & 80 & 300 & 100,00 & tinggi \\
\hline 6. & $\begin{array}{l}\text { Ketersediaan air } \\
\text { bersih }\end{array}$ & 390 & 900 & 170 & 900 & 100,00 & tinggi \\
\hline
\end{tabular}

Sumber : PHKA (2003a) 
Tabel 6. Matrik IFAS Pengembangan Ekowisata Salang Pangeran

\begin{tabular}{lccc}
\multicolumn{1}{c}{ Faktor-Faktor Internal } & Bobot & Rating & Skor \\
\hline Kekuatan: & & & \\
Daya Tarik Wisata & 0,11 & 4,0 & 0,44 \\
Aksesibilitas & 0,08 & 3,9 & 0,32 \\
Kesadaran Pelaku Wisata & 0,11 & 4,0 & 0,44 \\
Masyarakat Mendukung & 0,11 & 2,9 & 0,33 \\
Kondisi Kebersihan & 0,11 & 3,9 & 0,44 \\
Lembaga Pariwisata & 0,11 & 3,7 & 0,41
\end{tabular}

\begin{tabular}{lccc} 
Kelemahan: & & & \\
Penataan Kawasan & 0,11 & 1,0 & 0,11 \\
Pemasaran & 0,11 & 1,1 & 0,12 \\
Fasilitas Pariwisata & 0,06 & 1,9 & 0,10 \\
Kemampuan Pemodalan & 0,09 & 1,0 & 0,09 \\
\hline Total & 1,00 & & 2,80 \\
\hline Sum
\end{tabular}

Sumber : Rangkuti (2014)

terhadap konservasi alam (pemandu, pemilik penginapan, pemilik warung, dan biro perjalanan) cukup tinggi, pelaku wisata yang paling berperan adalah para pemandu. Saat ini para pemandu di bawah koordinasi Lembaga Ekowisata Salang Pangeran. Para pemandu berasal dari masyarakat lokal setempat serta pemandu dari ekowisata Bukit Lawang;

4. Masyarakat mendukung ekowisata, terdapat $101 \mathrm{KK}$, yang menjadi pemandu wisata sebanyak 16 orang, masyarakat yang lainnya mendukung dengan berbagai usaha seperti berjualan makanan dan minuman, menyediakan penginapan, menyediakan souvenir berupa obat-obatan tradisional, hasil kerajinan anyam-anyaman dan menyediakan jasa penyewaan ban;

5. Kondisi kebersihan dan ketersediaan air bersih di lokasi ekowisata Salang Pangerang cukup baik, dimana sumber air berasal dari Sungai Landak dengan hulu langsung dari dalam kawasan TNGL yang masih jernih dan terjaga kebersihannya.

6. Lembaga terkait pengelolaan pariwisata saat ini telah terbentuk yaitu Lembaga Ekowisata Salang Pangeran yang dibentuk sejak tahun 2014. Saat ini jumlah anggota lembaga sebanyak 50 orang termasuk pemandu / guide.
Hasil analisis IFAS di Ekowisata Salang Pangeran menunjukkan faktor-faktor internal yang menjadi kelemahan (weakness) adalah:

1. Penataan kawasan Ekowsiata Salang Pangeran masih belum disusun secara baik, peran lembaga ekowisata Salang Pangeran belum optimal dalam menyusun konsep penataan kawasan yang disepakati bersama;

2. Pemasaran Ekowisata Salang Pangeran masih kurang, hingga saat ini pemasaran yang dilakukan oleh pelaku wisata setempat masih kurang dan bergantung kepada travel agent dari luar daerah;

3. Fasilitas pariwisata masih belum lengkap, jaringan listrik di kawasan ekowisata belum tersedia, lokasi parkir khusus pengunjung belum disepakati, saat ini parkir masih berada di rumah-rumah penduduk, visitor center belum ada, musholla belum ada, lokasi berkemah dan tempat khusus penjualan produk-produk masyarakat belum ada.

4. Kemampuan pemodalan investasi masyarakat lokal masih terbatas, potensi pengembangan usaha untuk mendukung Ekowisata Salang Pangeran masih terbatas. Rumah makan dan warung kopi yang ada di lokasi masih sederhana. Juga pedagang kaki lima dan pedagang asongan yang berjualan terbatas saat hari libur dan tanggal merah; 
Tabel 7. Matrik EFAS Pengembangan Ekowisata Salang Pangeran

\begin{tabular}{lccc}
\hline \multicolumn{1}{c}{ Faktor-Faktor Eksternal } & Bobot & Rating & Skor \\
\hline Peluang: & & & \\
Trend Kembali Ke Alam & 0,14 & 4,0 & 0,56 \\
Kondisi Politik Stabil & 0,12 & 3,7 & 0,44 \\
Peranan Pemerintah & 0,13 & 3,0 & 0,39 \\
Kerjasama Pihak Lain & 0,13 & 4,0 & 0,52 \\
Minat Masyarakat Meningkat & 0,13 & 4,0 & 0,52 \\
Tidak Ada (TIPIHUT) & 0,14 & 2,9 & 0,41 \\
Pesaing Wisata Sejenis & 0,07 & 2,7 & 0,19 \\
& & & \\
Ancaman: & & & \\
Kondisi Ekonomi & 0,14 & 1,7 & 0,24 \\
\hline Total & 1,00 & & 3,27 \\
\hline Sumb: Rangkuti & & &
\end{tabular}

Sumber : Rangkuti (2014)

Hasil perhitungan skor terhadap analisis faktor-faktor internal dengan nilai sebesar 2,80 diketahui bahwa faktor-faktor internal di Ekowisata Salang Pangeran merupakan kekuatan. Strategi yang dapat digunakan dalam pengembangan Ekowisata Salang Pangeran adalah menggunakan kekuatan (Tabel 6).

\subsection{Analisis faktor-faktor eksternal}

Hasil analisis EFAS di ekowisata Salang Pangeran menunjukkan faktor-faktor eksternal yang menjadi peluang (opportunities) adalah:

1. Trend dunia kembali ke alam (back to nature), karakteristik destinasi Ekowisata Salang Pangeran sebagai destinasi alam maka sangat sejalan dengan trend dunia kembali ke alam;

2. Kondisi politik dan keamanan nasional dan internasional yang kondusif menyebabkan hambatan keamanan untuk berkunjung ke Indonesia sangat memudahkan, kebijakan penambahan jumlah negara yang bebas visa masuk ke Indonesia merupakan peluang yang besar, saat ini 174 negara mendapatkan bebas visa masuk Indonesia;

3. Peranan pemerintah dalam pengembangan ekowisata baik pemerintah daerah dan pemerintah pusat mulai ditingkatkan, walaupun untuk alokasi dana pengembangan di Ekowisata Salang Pangeran masih belum besar, dimana Ekowisata Salang Pangeran berada di desa penyangga
TNGL. Pemerintah daerah Kabupaten Langkat sudah memberikan bantuan papan informasi di pintu gerbang masuk kawasan ekowisata Salang Pangeran dan saat ini sudah memasukkan Ekowisata Salang Pangeran sebagai salah satu daerah tujuan wisata. Pemerintah telah mengatur prosedur pengusahaan pariwisata alam di kawasan suaka alam dan kawasan pelestarian alam sesuai Peraturan Pemerintah Nomor 36 Tahun 2010;

4. Kerjasama dengan pihak lain terbuka lebar, terutama kerjasama dalam meningkatkan jumlah wisatawan asing dan lokal melalui kerjasama dengan pemandu objek wisata yang telah maju di sekitar Salang Pangeran baik dari objek wisata Bukit Lawang maupun objek wisata Batu Katak.

5. Minat masyarakat untuk berwisata meningkat, hal ini ditandai dengan mulai ramainya jumlah kunjungan terutama pada saat tanggal merah dan hari-hari libur nasional. Kondisi alam yang masih asri dan bentang landscape hutan tropis TNGL merupakan potensi utama untuk menarik minat masyarakat berkunjung.

6. Tidak ada tindak pidana kehutanan (TIPIHUT), kondisi saat ini tidak ada aktivitas ilegal di kawasan TNGL yang berdekatan dengan Kawasan ekowisata Salang Pangeran merupakan peluang yang baik untuk pengembangan Ekowisata 
Tabel 8. Matrik SWOT

\begin{tabular}{|c|c|c|}
\hline Faktor Internal & $\begin{array}{l}\text { Strengths } \mathbf{S} \\
\text { 1. Daya tarik wisata tinggi } \\
\text { 2. Aksesibilitas terjangkau } \\
\text { 3. Kesadaran pelaku wisata } \\
\text { baik } \\
\text { 4. Masyarakat mendukung } \\
\text { ekowisata } \\
\text { 5. Kondisi kebersihan dan } \\
\text { ketersediaan air bersih } \\
\text { cukup baik pengelola } \\
\text { 6. Lembaga } \\
\text { pariwisata telah terbentuk }\end{array}$ & $\begin{array}{l}\text { Weakness W } \\
\text { 1. Penataan kawasan belum } \\
\text { dilakukan } \\
\text { 2. Pemasaran masih kurang } \\
\text { 3. Fasilitas pariwisata masih } \\
\text { kurang } \\
\text { 4. Kemampuan pemodalan } \\
\text { rendah }\end{array}$ \\
\hline $\begin{array}{l}\text { Opportunities O } \\
\text { 1. } \begin{array}{l}\text { Tren kembali ke alam } \\
\text { (back to nature) }\end{array} \\
\text { 2. Kondisi politik dan } \\
\text { keamanan kondusif } \\
\text { 3. Peranan pemerintah } \\
\text { dalam pengembangan } \\
\text { ekowisata ada } \\
\text { 4. Kerjasama dengan pihak } \\
\text { lain (Bukit Lawang dan } \\
\text { Batu Katak) terbuka } \\
\text { 5. Minat masyarakat untuk } \\
\text { berwisata meningkat } \\
\text { 6. Tidak ada Tindak Pidana } \\
\text { Kehutanan (TIPIHUT) } \\
\text { 7. Pesaing oleh destinasi } \\
\text { wisata sejenis kecil }\end{array}$ & $\begin{array}{l}\text { Strategi SO } \\
\text { 1. Menggunakan daya tarik } \\
\text { wisata alam, lokasi yang } \\
\text { mudah dijangkau, } \\
\text { kesadaran pelaku wisata, } \\
\text { dukungan masyarakat, } \\
\text { ketersediaan air bersih dan } \\
\text { lembaga pengelola yang } \\
\text { telah terbentuk untuk } \\
\text { memanfaatkan tren dunia } \\
\text { kembali ke alam dan nilai- } \\
\text { nilai tradisional. } \\
\text { 2. Menggunakan daya tarik } \\
\text { wisata alam, lokasi yang } \\
\text { mudah dijangkau, } \\
\text { kesadaran pelaku wisata, } \\
\text { dukungan masyarakat, } \\
\text { ketersediaan air bersih dan } \\
\text { lembaga pengelola yang } \\
\text { telah terbentuk dengan } \\
\text { memanfaatkan kondisi } \\
\text { politik dan kemanan yang } \\
\text { kondusif menjadi mitra } \\
\text { pemerintah dalam } \\
\text { pengembangan ekowisata. } \\
\text { Menjalin kerjasama dengan }\end{array}$ & $\begin{array}{l}\text { Strategi WO } \\
\text { 5. Penataan kawasan } \\
\text { melibatkan pemerintah } \\
\text { daerah, BBTNGL, dan } \\
\text { akademisi dalam menyusun } \\
\text { desain tapak dengan } \\
\text { meminimalkan dampak dan } \\
\text { tetap mempertahankan } \\
\text { kondisi alaminya. } \\
\text { 6. Bersama dengan } \\
\text { pemerintah dan pelaku } \\
\text { wisata lainnya dalam } \\
\text { meningkatkan pemasaran } \\
\text { serta fasilitas pariwisata } \\
\text { untuk memanfaatkan tren } \\
\text { dunia kembali ke alam dan } \\
\text { tren kembali ke tradisional } \\
\text { 7. Mendorong tumbuhnya } \\
\text { usaha kecil menengah } \\
\text { dengan memanfaatkan } \\
\text { program fasilitasi dari } \\
\text { pemerintah. }\end{array}$ \\
\hline $\begin{array}{l}\text { Threat T } \\
\text { 1. Kondisi ekonomi } \\
\text { nasional dan } \\
\text { internasional lesu, daya } \\
\text { beli masyarakat rendah }\end{array}$ & $\begin{array}{l}\text { pihak lain berupa objek } \\
\text { wisata di sekitar Salang } \\
\text { Pangeran agar menjadi } \\
\text { objek wisata berkualitas } \\
\text { dan maju dengan } \\
\text { memanfaatkan minat } \\
\text { masyarakat untuk berwisata } \\
\text { yang meningkat serta tidak } \\
\text { adanya TIPIHUT. } \\
\text { 4. Memanfaatkan daya tarik } \\
\text { wisata serta tidak adanya } \\
\text { tindak pidana kehutanan } \\
\text { untuk mencegah persaingan } \\
\text { antar objek wisata sejenis. }\end{array}$ & $\begin{array}{l}\text { Strategi WT } \\
\text { 9. Meningkatkan pemasaran } \\
\text { dengan membuat paket } \\
\text { wisata dengan harga } \\
\text { bersaing, pemasaran } \\
\text { menggunakan media masa } \\
\text { online dalam bahasa } \\
\text { Indonesia dan bahasa asing. }\end{array}$ \\
\hline & $\begin{array}{l}\text { Strategi ST } \\
\text { 8. Memanfaatkan daya tarik } \\
\text { wisata alam dan lembaga } \\
\text { pengelola wisata yang telah } \\
\text { terbentuk dengan } \\
\text { menawarkan wisata yang } \\
\text { ekonomis yang tetap } \\
\text { memuaskan. }\end{array}$ & \\
\hline
\end{tabular}


Salang Pangeran;

7. Pesaing oleh destinasi wisata sejenis yang berada di sekitar Ekowisata Salang Pangeran, seperti di Bukit Lawang dan Tangkahan merupakan peluang untuk membuat suatu paket bersama karena setiap lokasi memiliki keunikan masing-masing;

Hasil analisis EFAS di Ekowisata Salang Pangeran menunjukkan faktor-faktor eksternal yang menjadi ancaman (treath) adalah:

1. Kondisi ekonomi nasional dan internasional yang sedang menurun, krisis ekonomi melanda sejumlah negara di Eropa timur seperti di Jerman dan Yunani. Saat ini harga hasil perkebunan seperti kelapa sawit dan karet juga menurun. Kondisi ini mempengaruhi jumlah pengunjung. Ketidakpastian hukum juga merupakan hambatan dalam investasi di Indonesia.

Hasil perhitungan skor terhadap faktor-faktor eksternal dengan nilai sebesar 3,27 diketahui bahwa faktor-faktor eksternal di Ekowisata Salang Pangeran merupakan peluang. Strategi yang dapat digunakan adalah memanfaatkan peluang dalam pengembangan Ekowisata Salang Pangeran.

Peranan pemerintah yang mendukung pengembangan ekowisata merupakan peluang yang harus dimanfaatkan hal ini sesuai dengan penelitian Avenzora (2008) dan Sudana (2013) bahwa dukungan Pemerintah Daerah dengan berbagai kebijakan dan program pengembangan ekowisata. Pedoman dalam pengembangan ekowisata sudah diatur oleh Peraturan Menteri Dalam Negeri Nomor 33 tahun 2009 tentang pengembangan ekowisata di daerah.

\section{Analisis SWOT}

Hasil analisis faktor-faktor internal dan eksternal disintesis dalam Matrik SWOT untuk merumuskan strategi yang akan dijadikan pedoman dalam pengembangan Ekowisata Salang Pangeran (Tabel 8).

\section{Prioritas Pengembangan}

Berdasarkan hasil sintesis pada matrik SWOT dilakukan prioritas rencana pengembangan dengan mengacu kepada Arifin (2012) dan Attar et al. (2013) dirumuskan 9 alternatif strategi untuk rencana pengembangan ekowisata Salang Pangeran yang dapat diuraikan sebagai berikut :

1. Menggunakan daya tarik wisata alam, lokasi yang mudah dijangkau, kesadaran pelaku wisata, dukungan masyarakat, ketersediaan air bersih dan lembaga pengelola yang telah terbentuk untuk memanfaatkan tren dunia kembali ke alam dan nilai-nilai tradisional;

2. Menggunakan daya tarik wisata alam, lokasi yang mudah dijangkau, kesadaran pelaku wisata, dukungan masyarakat, ketersediaan air bersih dan lembaga pengelola yang telah terbentuk dengan memanfaatkan kondisi politik dan kemanan yang kondusif menjadi mitra pemerintah dalam pengembangan ekowisata;

3. Menjalin kerjasama dengan pihak lain berupa objek wisata di sekitar Salang Pangeran agar menjadi objek wisata berkualitas dan maju dengan memanfaatkan minat masyarakat untuk berwisata yang meningkat serta tidak adanya TIPIHUT;

4. Memanfaatkan daya tarik wisata serta tidak adanya tindak pidana kehutanan untuk mencegah persaingan antar objek wisata sejenis;

5. Penataan kawasan melibatkan pemerintah daerah, BBTNGL, dan akademisi dalam menyusun desain tapak dengan meminimalkan dampak dan tetap mempertahankan kondisi alaminya;

6. Bersama dengan pemerintah dan pelaku wisata lainnya dalam meningkatkan pemasaran serta fasilitas pariwisata untuk memanfaatkan tren dunia kembali ke alam dan tren kembali ke tradisional;

7. Mendorong tumbuhnya usaha kecil menengah dengan memanfaatkan program fasilitasi dari pemerintah;

8. Memanfaatkan daya tarik wisata alam dan lembaga pengelola wisata yang telah terbentuk dengan menawarkan wisata yang ekonomis yang tetap memuaskan;

9. Meningkatkan pemasaran dengan membuat paket wisata dengan harga bersaing, pemasaran menggunakan media masa online dalam bahasa Indonesia dan bahasa asing. 


\section{Kesimpulan dan Saran}

\subsection{Kesimpulan}

Hasil analisis ODTWA di kawasan ekowisata Salang Pangeran diketahui nilai potensi untuk kriteria daya tarik, akomodasi, sarana prasarana penunjang dan ketersediaan air bersih dengan nilai tinggi, sedangkan kriteria aksesibilitas dan kondisi lingkungan sosial ekonomi dengan nilai sedang.

1. Faktor-faktor internal yang mempengaruhi pengembangan Ekowisata Salang Pangeran merupakan kekuatan dengan skor 2,80 yaitu daya tarik wisata, aksesibilitas, kesadaran pelaku wisata, masyarakat mendukung ekowisata, kondisi kebersihan, dan lembaga pariwisata. Faktor-faktor eksternal merupakan peluang dengan skor 3,27 yaitu trend kembali ke alam, kondisi politik stabil, peranan pemerintah, kerjasama pihak lain, minat masyarakat meningkat, tidak ada TIPIHUT, dan pesaing wisata sejenis;

2. Terdapat 9 alternatif strategi dalam pengembangan Ekowisata Salang Pangeran sebagai daerah penyangga Taman Nasional Gunung Leuser. Strategi yang diprioritaskan adalah memanfaatkan tren dunia kembali ke alam dan kembali ke nilai-nilai tradisional, menjadi mitra pemerintah dalam pengembangan ekowisata, dan mendorong tumbuhnya usaha kecil menengah dengan memanfaatkan program fasilitasi dari pemerintah;

\subsection{Saran}

1. Pemerintah daerah dan instansi terkait lainnya perlu segera menyusun desain tapak sesuai dengan kondisi lingkungan, daya dukung kawasan dan perencanaan interpretasi di dalam kawasan Taman Nasional Gunung Leuser. Perencanaan desain tapak disesuaikan dengan jenis wisata alam yang akan dikembangkan di setiap objek prioritas seperti wisata memancing, pemandian, rafting, tubing untuk objek Sungai Landak, wisata trekking, camping, pengamatan flora fauna khas TNGL untuk objek Air Terjun Salang Pangeran serta wisata penelusuran gua, camping dan pengamatan fauna gua di objek Gua Batu Rizal;

2. Diperlukan penggalian potensi yang berada di kawasan Taman Nasional Gunung Leuser terutama lokasi yang akan diusulkan untuk menjadi zona pemanfaatan. Jalur trekking dan pengamatan satwa liar dalam kawasan Taman Nasional Gunung Leuser untuk lebih menambah daya tarik dan atraksi wisata dengan tetap mempertahankan kondisi alaminya;

\section{Daftar Pustaka}

Arifin, S. 2012. Hukum Perlindungan Dan Pengelolaan Lingkungan Hidup. Jakarta: PT SOFMEDIA.

Avenzora, R. 2008. Ekotourism evaluasi Tentang Konsep. Di dalam Avenzora R, editor. Ecotourism Teori dan Praktek. Banda Aceh : BRR NAD-NIAS.pp 1-18.

Attar, M., Hakim, L., Yanuwiadi, B. 2013. Analisis Potensi Dan Arahan Strategi Kebijakan Pengembangan Desa Ekowisata di Kecamatan Bumiaji-Kota Batu. Journal of Indonesian Tourism and Development Studies 1(2) : 68-78.

[BAPPEDA] Badan Perencanaan Pembangunan Daerah. 2013. Rencana Tata Ruang Wilayah Kabupaten Langkat 2013-2033. Pemerintah Daerah Langkat. Stabat.

[BPMD] Badan Pemberdayaan Masyarakat Desa. 2016. Profil Desa Tahun 2016. Desa Timbang Lawan Kecamatan Bohorok. Pemerintah Kabupaten Langkat.

Beljai, M., Muntasib, E.K.S.H.,Sulistyantara, B. 2014. Konsep Pentaan Lanskap Untuk Wisata Alam di Kawasan Taman Wisata Alam Sorong. Jurnal Manusia dan Lingkungan. 21 (3) : 356-365

[BBTNGL] Balai Besar Taman Nasional Gunung Leuser. 2016. Statistik Balai Besar Taman Nasional Gunung Leuser Tahun 2016. BBTNGL. Medan

[BPS] Badan Pusat Statistik Kabupaten Langkat. 2016. Kecamatan Bohorok Dalam Angka 2016. BPS. Stabat

MacKinnon, J., MacKinnon, K., Child, G., Thorsell, J. 1993. Pengelolaan Kawasan 
Yang Dilindungi di Daerah Tropika. Amir $\mathrm{HH}$, penerjemah. Ed ke-2. Yogyakarta : Gajah Mada University Press. Terjemahan dari : Managing Protected Areas in the Tropics.

Nugraha, B., Banua, I, S.,Widagdo, S. 2015. Perencanaan Lanskap Ekowisata Hutan Mangrove di Pantai Sari Ringgung Desa Sidodadi Kecamatan Padang Cermin Kabupaten Pesawaran. Jurnal Sylva Lestari. 3 (2) : 53-66

[PHKA] Direktorat Jenderal Perlindungan Hutan dan Konservasi Alam. 2002. Kriteria Penilaian dan Pengembangan Objek dan Daya Tarik Wisata Alam. Bogor : PHKA

[PHKA] Perlindungan Hutan dan Konservasi Alam. 2003 (a). Pedoman Analisis Daerah Operasi Obyek dan Daya Tarik Wisata Alam (ADO-ODTWA). Direktorat Jenderal

Perlindungan Hutan dan Konservasi Alam. Bogor.

[PHKA] Perlindungan Hutan dan Konservasi Alam. 2003 (b). Informasi, Promosi dan Peluang Usaha di Taman Nasional. Direktorat Jenderal Perlindungan Hutan dan Konservasi Alam. Bogor.

Purnomo, H., Sulistyantara, B., dan Gunawan, A. 2013. Peluang Usaha Ekowisata di Kawasan Cagar Alam Pulau Sempu, Jawa Timur. Jurnal Penelitian Sosial Dan Ekonomi Kehutanan. 10 (4) : 247-263.

Rahantoknam, S, P, T., Nurisjah, S., Yulianda, F. 2012. Kajian Potensi Sumberdaya Alam dan Lingkungan Untuk Membangun Ekowisata Pesisir Nuhuroa Kabupaten Maluku Tenggara. Jurnal Lanskap Indonesia. 4 (1) : 29-36

Rangkuti, F. 2000. Analisis SWOT Teknik Membedah Kasus Bisnis. Jakarta : PT Gramedia Pustaka Utama

Rangkuti, F. 2014. Analisis SWOT Teknik Membedah Kasus Bisnis (Cara Perhitungan Bobot, Rating, dan OCAI). Jakarta : PT Gramedia Pustaka Utama

Romani, S. 2016. Penilaian Potensi Obyek dan Daya Tarik Wisata Alam Serta Alternatif Perencanaannya di Taman Nasional Bukit Dua Belas Provinsi Jambi. Tesis. Institut Pertanian Bogor. Bogor.
Sudana, I, P. 2013. Strategi Pengembangan Wisata Ekologis Di Desa Belimbing, Kecamatan Pupuan, Kabupaten Tabanan. Analisa Pariwisata. 13 (1) : 11-31.

[UNESCO] United Nation Educational, Scientific, and Cultural Organization. 2011. Convention Concerning The Protection of World Cultural and Natural Heritage (Tirhty-Fifth Session). UNESCO. Paris

Wind, J. 1996. Gunung Leuser National Park: History, Threats, and Options in Leuser a Sumatran Sanctuary. Ed. Schaik, C,V., Supriatna, J. YBSHI. Jakarta, pp. 25

Wiranantha, A, S., Dalem, A, A, G, R., Pujaastawa, I, B, G., Madiun, N., Isdaryono. 2009. Pengembangan Ekowisata Taman Nasional Gunung Leuser. Yayasan Bali Greenery. Jakarta.

Zahedi. 2002. Studi Karakteristik dan Potensi Pengembangan Gua-Gua Karst di Kecamatan Bahorok Kabupaten Langkat (Tesis). Medan: Universitas Sumatera Utara, Program Pascasarjana. 